\title{
O DISCURSO INTERACIONAL EM SALA DE AULA DE LÍNGUA ESTRANGEIRA
}

\section{Roseanne Rocha Tavares ${ }^{(*)}$}

Resumo: Este trabalho tem por objetivo apresentar algumas considerações teóricas acerca da estrutura discursiva de professores e alunos em sala de aula de línguas estrangeiras (LE) com base nos fundamentos da Pragmática, da Sociolingüística Interacional e da Lingüística Aplicada.

Palavras-chave: Ensino e aprendizagem de línguas estrangeiras; interação; estrutura discursiva; sala de aula

Para entendermos com mais clareza a complexidade do processo de ensinar e aprender línguas estrangeiras, é necessário refletirmos acerca dos multicomponentes que o integram. Muito mais do que transmitir conhecimentos gramaticais a seus alunos, seguindo aqui uma concepção clássica de ensino de LE, é imprescindível que o professor conheça os componentes socioculturais que fazem parte deste processo. O próprio discurso do professor e dos alunos envolve uma série de negociações que se delineiam na caracterização, entre outros elementos, da estrutura discursiva de sala de aula. O objetivo deste trabalho é, à luz dos fundamentos teóricos da Pragmática, da Sociolingüística Interacional e da Lingüística Aplicada, refletir acerca de tal estrutura discursiva.

A sala de aula de língua estrangeira é definida por van Lier (1988, p.47) como “... a reunião, por um determinado período, de duas ou mais pessoas (uma das quais geralmente assume o papel de instrutor [sic]), objetivando o aprendizado de uma língua". Nessa reunião, encontram-se como participantes o professor, os aprendizes e, de maneira mais indireta, os autores dos textos utilizados em sala de aula (já que muitas vezes, dependendo do perfil da aula, o professor não adota apenas um livro-texto como guia). Além da referência aos

(*) Professora do Programa de Pós-Graduação em Letras e Lingüística da Universidade Federal de Alagoas. Atua na área de ensino-aprendizagem de línguas estrangeiras. 
participantes, Malamah-Thomas (1987) aponta outros elementos que caracterizam esse evento. Esses elementos explicam, segundo o referido autor, e aqui se percebe uma influência dos fundamentos teóricos da Pragmática sobre o discurso, quem diz o que, para quem diz, por que e como algo é dito.

Ainda de acordo com Malamah-Thomas (1987), acerca do que se diz em sala de aula, existem três tipos de conteúdo discursivo: o primeiro, o conteúdo pedagógico, visa à transmissão de conhecimento da língua-alvo. Tal tipo de conteúdo discursivo, a nosso ver, deve considerar as relações do sujeito-aprendiz e do sujeito-professor com o contexto social e histórico do qual eles fazem parte. As questões da própria vivência devem estar em confronto/análise com as questões socioculturais da língua alvo. O segundo conteúdo, o conteúdo relacionado à manutenção da harmonia em sala de aula, caracteriza-se por tentar promover uma boa atmosfera e um senso de comunidade entre os participantes; finalmente, há o conteúdo relacionado aos objetivos organizacionais e administrativos da sala de aula.

O conteúdo do que é dito em sala de aula está profundamente relacionado com seus objetivos. Pode-se dizer que há três motivos para que se diga algo em uma sala de aula. O primeiro motivo, e o mais importante, é o pedagógico. Ele é o principal fator que distingue a sala de aula de outros contextos. Tanto o professor como o aprendiz se comunicam, na maioria das vezes, objetivando a aprendizagem. O professor, por exemplo, apresenta novas propostas de conteúdo que podem ser desenvolvidas pela turma para alcançar uma melhor aprendizagem da língua. Os aprendizes, por outro lado, repetem. respondem e questionam sobre o conteúdo da lição. Algumas vezes, promovendo uma relação mais simétrica em sala de aula, os aprendizes também mudam, sugerem e adaptam os conteúdos conforme os seus objetivos e necessidades. O segundo motivo do exercício da comunicação em sala de aula é o pessoal. Todos os participantes tentam estabelecer e manter uma relação pessoal entre si. seja ela autoritária ou tolerante, formal ou informal. O terceiro motivo relaciona-se com a necessidade de organizar e administrar o evento, como, por exemplo, fazer a chamada, arrumar as carteiras etc.

O que Malamah-Thomas chama de conteúdo com objetivo pedagógico é denominado por Cazden (1988) a linguagem do curriculum, que comunica e informa, que exerce a funçĩo proposicional no discurso pedagógico. A segunda função é a 
expressiva, que tem como ação a expressão da identidade e atitude de cada falante. A pessoa que não adere às regras é de alguma forma estigmatizada, como os idosos às vezes são pelos jovens ao não compartilharem os mesmos valores e linguagem (Preti, 1996). Há também para Cazden uma terceira função: a social. Isto se deve ao fato de o contexto de sala de aula além de ter a capacidade de reunir durante pelo menos cinqüenta minutos um número significativo de pessoas em um mesmo ambiente, como ocorre em restaurantes, boates e ônibus, também estabelecer regras conversacionais específicas para esse tipo de instituição cujo controle da fala de cada integrante geralmente é assegurado pelo professor. Essas, segundo a autora, seriam as três funções predominantes no discurso de sala de aula, não deixando de levar em consideração que todo discurso é multifuncional.

Por fim, os recursos utilizados para estabelecer a comunicação são as línguas (materna e estrangeira), e os recursos não-verbais, gestos, sinais, fotos, desenhos etc.

Uma das primeiras ações em sala de aula é o seu próprio planejamento. No entanto, a ação desse planejamento só implicará bons resultados pedagógicos a partir das ações dos aprendizes. Essas ações ocorrem de diversas maneiras: eles repetem ou não o que foi pedido, seguem ou não as instruções, tomam iniciativas etc. O professor tem de estar atento às ações de seus aprendizes, sabendo que existe uma diferença entre planejamento e execução; cf.. Malamah-Thomas, 1987; Tsui, 1995. Allwright e Bailey (1991) usam o termo "descarrilamento" (derailment) para descrever aulas que não acontecem de acordo com o que foi planejado, o que, a nosso ver, se dá em praticamente todas. No entanto, a desenvoltura do professor para aproveitar as idéias dos aprendizes e modificar os planos da aula é um passo importante. Os participantes de uma sala de aula não chegam "de mãos vazias". Os aprendizes trazem suas experiências de aprendizagem e de vida, suas próprias necessidades e razões para aprender. As expectativas do aprendiz em relação a como deve ser o papel do professor e à aquisição de uma nova língua e o medo de fracasso pessoal também vão influenciar na interação. Já o professor traz seu conhecimento de mundo e de sala de aula. Também traz, algumas vezes em conjunto com o autor do livro-texto e de acordo com a política de ensino da escola, o programa, o método de ensino, entre outros recursos pedagógicos. A execução prática desse planejamento depende de como esses elementos 
interagem. Por exemplo, o programa escolhido depende do insumo (input) que os aprendizes tiveram em sala de aula; o método depende das oportunidades práticas; e a atmosfera depende da receptividade dos participantes.

\section{Interação e insumo}

Segundo Allwright e Bailey (1991, p.120), a palavra "insumo refere-se à língua que os aprendizes escutam (ou lêem) - isto é, as amostras de língua às quais eles são expostos para aprendizagem". Para Krashen (1982), nem todo insumo apresentado em sala de aula é compreendido. Apenas uma determinada porção faz sentido e é passível de promover o aprendizado. Para ele, o insumo compreensível (comprehensible input) é denominado $\mathbf{i}+1$, onde $\mathbf{i}$ representa o estado atual da interlíngua desenvolvida pelo aprendiz e +1 designa o insumo novo, mas não opressivo. Já para Bruner (apud Moita Lopes, 1996), o insumo é também considerado o conhecimento adquirido pelo aluno acerca dos modos de aprender para operar na sala de aula, de forma bem-sucedida. Contudo, não é apenas a exposição ao insumo que promove o aprendizado. O esforço feito pelo aprendiz para compreendê-lo e, conseqüentemente, o esforço do professor para que o aprendiz compreenda é que promovem o aprendizado. Esse esforço é influenciado pela interação em sala de aula.

A interação é um processo de duas vias, o qual tem o potencial para a cooperação ou para o conflito. O seu direcionamento dependerá das atitudes e intenções das pessoas envolvidas e da interpretação que elas fazem das intenções e atitudes dos outros, como explica Malamah-Thomas (1987). Em sala de aula, a interação é administrada de maneira tal que o aprendizado ocorra. Além do insumo, a aprendizagem também dependerá da estrutura discursiva aplicada na interação.

\section{A estrutura discursiva em sala de aula}

$\mathrm{Na}$ interação em sala de aula ocorre uma série de ajustes na tentativa de entender e de ser entendido. A maioria desses ajustes é feita através da fala, colocada então como peça central no sistema comunicativo. Segundo Kramsch (1987), o discurso em sala de aula se move entre dois pólos de um continuum de opções instrucionais. De um lado, tem-se o discurso instrucional, no qual os participantes têm papéis fixos, as tarefas são centradas no professor e a ênfase é dada ì 
quantidade de conteúdo ensinado e à precisão. Do outro lado, há o discurso espontâneo, com seus papéis negociados, com as tarefas orientadas pelo grupo e com o conhecimento concentrado no processo de aprendizagem e na fluência interacional. Para a autora, o mais indicado seria que, em sala de aula, os participantes conseguissem atingir um "discurso de convívio" que não estivesse em nenhum desses dois extremos do continuum, mas que aliasse elementos dos dois pólos de forma balanceada e frutífera para o aprendizado. No entanto, na maioria das vezes, a realidade é diferente. De acordo com Sinclair e Coulthard (1975), em salas de aula consideradas tradicionais, o padrão mais comum no discurso é a sequiência iniciação/resposta/avaliação (IRA), que também é um dos elementos caracterizadores de um discurso institucional. Cazden (1988) afirma que esse padrão pode ser reconhecido por qualquer pessoa como uma característica da "fala" de sala de aula, diferenciando-se da conversação espontânea.

Essa estrutura tríplice aparece em aulas cujos professores exercem forte controle na distribuição do turno e no desenvolvimento do tópico. O mesmo se aplica às aulas de língua estrangeira. Como afirma Gonçalves (1995, p.267) "senhores absolutos do discurso, os professores de línguas estrangeiras mantêm o controle conversacional durante a aula e se encarregam de dirigir a interação, assinalando o começo, o meio e o fim dos diversos estágios ou atividades, bem como o começo e o fím dos diálogos, o controle da vez de falar, aceitando ou sancionando as respostas dos aprendizes". Segundo o mesmo autor, esse tipo de estrutura organizacional do discurso reflete o tríplice papel do professor:

1) O papel de vetor da informação, isto é, o professor é o informante, o gerador do input linguiístico para o aprendiz; é o professor que explicita os conteúdos, explica e faz os aprendizes se apropriarem dos dados, através da metalíngua;

2) O papel do animador, líder do jogo interacional, com a incumbência de organizar, estruturar e dirigir a interação;

3) O papel do avaliador, encarregado de arbitrar a produção e verificar a aprendizagem, sancionando ou recompensando o desempenho dos aprendizes. 
Com tantas funções, o professor acaba sendo o participante que produz metade ou mais do discurso em sala de aula (ALLWRIGHT e BAILEY, 1991). Paradoxalmente, o número de aprendizes para cada professor, inclusive em aulas de língua inglesa, passa de 15, alcançando facilmente o total de 30 aprendizes, para sermos otimistas, em salas de aula de escolas públicas ou privadas do ensino médio. Segundo Shuy (1988), esta é uma das principais diferenças entre o discurso de sala de aula e o de outros contextos. principalmente das conversas do cotidiano. Enquanto o primeiro se destaca por apresentar uma média de 30 pessoas para uma apenals, o segundo é caracterizado pela estrutura de uma para outra pessoa.

A estrutura geral de uma aula já foi estudada de duas maneiras: por meio da dimensão seqüencial ou da dimensão seletiva. A primeira, estudada detalhadamente por Mehan (1979, in CAZDEN. 1988), caracteriza-se pela análise sintagmática e horizontal da estrutura da sala de aula. Como um cardápio de restaurante, que tem um conjunto de categorias alinhadas em determinada ordem (petiscos. prato principal, sobremesa), a aula também é categorizada em abertura, instrução e fechamento. Essas categorias são constituídas por sequiências instrucionais, seqüências básicas, conjunto de tópicos relacionados, fases e lição. A segunda dimensão, estudada por Sinclair e Coulthard (1975), prioriza a análise paradigmática e vertical da estrutura da aula. Ao enfatizar o estudo das escolhas discursivas por meio da aplicação da teoria dos atos de fala, desenvolvida por Austin (1962), os autores perceberam, por exemplo, que, na sequiencia estrutural iniciação/resposta/avaliação, a iniciação pode ser apresentada em forma de perguntas, de declarações afirmativas ou de imperativos, constatando-se, assim, a imensa variedade de opções lingüísticas em uma locução. Cazden (1988) afirma que ambas as dimensões devem ser levadas em consideração ao analisar-se uma aula, podendo dar maior ênfase a uma ou a outra. Os padrões discursivos encontrados por meio dessas dimensões permitem que se analisem as semelhanças e diferenças discursivas entre o contexto de sala de aula e outros contextos, como, por exemplo, a hora das refeições em casa; cf. Shultz, Florio e Erickson, 1982. Também permitem uma caracterização mais aprofundada da fala do professor c dos aprendizes. 


\section{A fala do professor e dos aprendizes}

Como foi dito, em uma aula tradicional, o professor é o participante que mais fala. Ele também determina o tópico e inicia a maioria das perguntas e pedidos, restando ao aprendiz um papel passivo por meio do qual ele responde às perguntas e obedece às instruções.

Pesquisas sobre a fala do professor mostram que o seu discurso pode ser classificado como registro, isto é, "um modo de falar convencionalizado e utilizado em lugares específicos" (HEATH, 1978, p.2), como, por exemplo, a fala de um adulto com um bebê, de enfermeiras com pacientes, entre outros. Toda fala "registro" tem elementos próprios que a caracterizam como tal. Esses elementos podem pertencer a diferentes níveis lingüísticos, como o fonológico, o sintático, e assim por diante. A fala do professor é caracterizada pelo exagero na entonação, pela fala mais pausada que o normal e mais claramente pronunciada, com mais repetições, sintática e lexicalmente mais simples, e com grande enfase na expressão do controle da interação por meio de funções metacomunicativas, como chamar a atenção, controlar os turnos etc.; por exemplo, Heath, 1978; Cazden, 1988; Allwright e Bailey, 1991; Tsui, 1995. Alguns estudiosos argumentam que essa fala não é natural, difere de situações comunicativas espontâneas e, consequientemente, não é o exemplo ideal de fala para o aprendiz ouvir (KRAMSCH, 1987). É o que Gonçalves (1995) chama de paradoxo do aprendiz de segunda línguil, que deve adquirir uma competência comunicativa natural, exposto ao ambiente artificial da sala de aula. No entanto, o que mais prejudica o processo de aquisição de uma LE são as estratégias utilizadas em sala de aula: os tipos de perguntas, de explicações e de avaliações (feedback) feitas pelo professor e pouco utilizadas pelos aprendizes..

As perguntas são um aspecto importante do discurso em sala de aula. A maior parte da interação é originada por perguntas feitas pelo professor. Elas são utilizadas para checar a compreensão, chamar a atenção do aprendiz e envolvê-lo na aula, exercitar o controle, praticar certos itens lingüísticos e utilizar a língua-alvo para comunicar. Estudos sobre perguntas propuseram várias categorias de acordo com fatores como demanda cognitiva e efeitos nos estudantes. Elas podem ser abertas ou fechadas, de exposição (display.) ou referenciais. As perguntas de exposição são feitas para checar e expor o conhecimento dos aprendizes; as perguntas referenciais sĩo 
consideradas perguntas espontâneas cujas respostas o professor não sabe (TSUI, 1995).

Já as explicações se enquadram na tentativa de fornecer aos outros a compreensão de uma determinada questão. A explicação pode ser gramatical ou lexical. Em ambas, o professor deve conhecer o nível de competência do aprendiz para saber até que ponto a explicação pode ser elaborada. Uma explicação eficiente envolve o nível de envolvimento do aprendiz com o processamento da informação e com o relacionamento da informação antiga com a nova (KRASHEN, 1982).

$\mathrm{Na}$ avaliação (feedback), o professor faz comentários a respeito do desempenho do aprendiz. Também pode reconhecer a informação dada por este aprendiz e fornecer comentários pessoais. $\mathrm{O}$ tipo de avaliação afeta o aprendizado. Se o professor fornecer constantemente uma avaliação negativa, pode gerar um sentimento de fracasso e frustração entre aprendizes. Se for encorajadora, faz com que os aprendizes fiquem motivados a participar, criando uma atmosfera agradável.

Ao contrário da hegemonia da fala do professor, a fala dos aprendizes, especialmente nas aulas mais tradicionais, é limitada. Geralmente, é o professor quem distribui os turnos, mantendo a maioria a seu favor. Quando estabelece outro interlocutor, ele o faz por meio de nominação individual ("Aline, convide seu colega"); ou por meio de nominação geral ("quem poderia responder a essa questão?"). Esse tipo de distribuição de turno em sala de aula é um bom exemplo da metáfora sugerida por Mehan e apresentado por Cazden (1988) em seu livro. Para Mehan, a escola é um espetáculo constituído por um grupo de atores ${ }^{1}$. No entanto, apenas o professor sabe o roteiro (ou pensa que sabe), assumindo, assim, a função de diretor e ator principal. Aparentemente, ele é o único "falante nativo" da "cultura" de sala de aula. Porém, o seu desempenho depende do desempenho dos aprendizes, dos "imigrantes", que, para serem rapidamente aceitos, devem adotar a fala de aprendiz esperada pelo professor e aprender as regras e convenções da "cultura" da sala de aula. Seguindo esse pensamento, os aprendizes devem obedecer à

A idéia de comparar interação com um espetáculo e seus participantes com atores foi apresentada por Goffman no livro The presentation of self in everyday life (1959) e chamada, na sociologia, de perspectiva teatral. 
estrutura IRA, devem falar as frases certas, no momento certo, e sintaticamente corretas. À medida que os aprendizes vão adquirindo uma competência comunicativa da "cultura" de sala de aula, eles passam a falar de acordo com o imposto pelo professor, mas em benefício próprio, gerando participações que não se restringem a repetições e respostas em uníssono, mas também incluem antecipações de instruções, elaborações de pensamento e de locuções, pedidos de ajuda, e outras estratégias de aprendizagem. Contraditoriamente, alguns professores não aceitam esse tipo de participação, talvez por acharem que estão perdendo o controle da interação.

\section{Estruturas alternativas e contexto}

Até agora foram descritos a estrutura e o discurso de salas de aula tradicionais, nas quais, retomando a metáfora de Mehan, a cultura escolar é cheia de regras e convenções a ser seguida, e o professor é visto como falante "nativo" enquanto os aprendizes são os "imigrantes" que devem estabelecer-se na nova cultura. Cazden (1988) afirma que devemos observar os limites de tal paradigma. Como em toda situação interacional, as salas de aula são "culturas especiais" cujas normas e regras que guiam o discurso do professor e do aluno em sala de aula devem estar sempre em conformidade com a dinamicidade do contexto, dando vez às improvisações e às estruturas alternativas.

Como foi dito anteriormente neste trabalho, toda situação social tem, em seus participantes, atores sociais cujos papéis são ativos na elaboração da interação, constituindo um significado social no encontro e fazendo de seu contexto um processo passível de modificações ao longo do percurso interacional. Para Moita Lopes (1996), um dos fatores que promovem tal ação social em sala de aula é a construção do conhecimento de forma colaborativa. Vimos que o professor e algumas vezes o aluno têm um conhecimento prévio do que seja ensinar e aprender em sala de aula de LE. Entretanto, esse conhecimento é reelaborado à medida que os participantes de uma sala de aula interagem e passam por "... um processo que envolve controle, negociação, compreensão e falhas na compreensão entre aluno e professor até que passa a fazer parte do conhecimento compartilhado na sala de aula" (p.96). O autor acrescenta que a construção desse conhecimento compartilhado não é uma atividade simples de ser executada. Concordamos com o pensamento de Moita Lopes, que diz 
que, para a construção desse tipo de conhecimento operar, é necessário que adotemos uma postura educacional distinta tanto da atitude tradicional colocada no papel do professor como da "chamada aprendizagem centrada no aprendiz, posto que interação implica ação conjunta para o desenvolvimento de conhecimento comum" (p.96).

É nesse tipo de interação de sala de aula que encontramos seqüências distintas da IRA. Seqüências cujos turnos são iniciados pelos alunos e cujo discurso se assemelha às conversações espontâneas. Essas estruturas discursivas alternativas que, pode-se dizer, se enquadram no "discurso de convívio" sugerido por Kramsch (1987) resgatam alguns dos direitos dos aprendizes. Sobre esse tema, podem-se conferir os trabalhos de Gomes de Matos (1984; 1986 a,b; 1996). O autor (1984) sugere que aprendizes de línguas têm o direito fundamental de poder comunicar-se e expressar-se em sua língua materna. Esse direito deve ser transferido quando se trata, mais especificamente, de aprendizes de línguas estrangeiras. O autor oferece uma lista, não exaustiva, de nove direitos lingüísticos de aprendizes de língua inglesa, que podem ser transferidos para qualquer língua estrangeira (1986, p.9). São eles: a) aprender uma segunda língua (ou língua estrangeira); b) escolher a variedade lingüística nacional a ser aprendida; c) escolher que habilidades lingüísticas adquirir (ou, se preferir, adquirir todas); d) compreender; e) usar dicionários bilíngües na sala de aula ao fazer exercícios; f) usar um estilo de aprendizagem que seja o preferido em sala de aula; g) receber explicações sobre o funcionamento e uso da língua; h) ser testado de maneira correta e relevante; i) negociar contratos de aprendizagem da língua onde os direitos do aprendiz e suas necessidades estejam especificados.

As estruturas discursivas do tipo "convívio" também caracterizam o que entendemos ser o real ensino de língua estrangeira, cuja definição, dada por Almeida Filho (1993, p.11-12), adotamos neste trabalho:

Pode significar língua dos outros ou de outros, ou língua de antepassados, de estranhos, de bárbaros, de dominadores, ou língua exótica. A compreensão do termo se aperfeiçoa se o tomarmos como língua que só a princípio é de fato estrangeira mas que se desestrangeiriza ao longo do tempo de que se dispõe para aprendê-la. Essa nova língua pode ser tida em melhor perspectiva como 
uma língua que também constrói o seu aprendiz e em algum momento futuro vai não só ser falada com propósitos autênticos pelo aprendiz mas também 'falar esse mesmo aprendiz', revelando índices da sua identidade e das significações próprias do sistema dessa língua-alvo.

É através do estudo dos elementos que levam ao processo de desestrangeirização da língua-alvo que alcançaremos uma visão mais crítica do que seja ensinar e aprender uma língua estrangeira em um contexto do tipo sala de aula cuja institucionalidade apresenta certas normas sociais e discursivas que influenciam a própria situação interacional. Com base nesse jogo de linguagem, parece-nos que o papel do professor envolve uma vontade de constituir um ambiente ideal para a aquisição de uma língua estrangeira. Conhecer a estrutura discursiva da sala de aula nos certifica da complexidade inerente ao processo de ensinar e aprender uma língua estrangeira.

\section{Referências bibliográficas}

ALLWRIGHT, D.; BAILEY, K. Focus on the language classroom. Cambridge: Cambridge University Press, 1991.

Almeida Filho, J. C. P. de. Dimensões Comunicativas no ensino de línguas. Campinas, São Paulo: Pontes, 1993.

AUSTIN, J. L. Quando dizer é fazer. Tradução do original How to do things with words de 1962 por Danilo Marcondes de Souza Filho, Porto Alegre: Artes médicas, 1990.

CAZDEN, C. B. Classroom discourse: the language of teaching and learning. Portsmouth, NH: Heinemann, 1988.

GOFFMAN, E. The presentation of self in everyday life. New York: Anchor Books, 1959.

GOMES DE MATOS, F. A importância dos direitos lingiísticos do aprendiz. Interação. São Paulo: Yázigi, p. 16-19, junho-julho 1984.

GOMES DE MATOS, F. A gap in ESL pedagogy: learner's rights.Tesol Newsletter. p.9, April 1986a. 
GOMES DE MATOS, F. The linguistic rights of English language learner in Brazil: a new frontier. Anais do I Encontro Regional de Professores Universitários de Língua Inglesa. Rio de Janeiro: PUC, Departamento de Letras, 30/07 a 01/08, p.13-25, 1986b.

GOMES DE MATOS, F. A human rights approach to teacher training. The Teacher Trainer, vol. 10, n.2, 1996.

GONÇALVES, J.C. O tópico discursivo no discurso institucionalizado. Investigações, 5: 263-285, 1995.

HEATH, S. B. Teacher talk: language in the classroom. Language in Education:theory and practice, 9, Virginia: Center for applied linguistics, 1978.

$\mathrm{KRAMSCH}, \mathrm{C}$. Interactive discourse in small and large groups. IN: W. Rivers (ed.). Interactive language teaching. Cambridge: Cambridge University Press, 1987.

KRASHEN, S. D. Principles and practice in second language acquisition. Oxford: Pergamon Press, 1982.

van LIER, L. The classroom and the language learner: ethnography and second language classroom research. London: Longman, 1988.

MALAMAH-THOMAS, A. Classroom interaction. Oxford: Oxford University Press, 1987.

MEHAN, H. Learning lessons: social organization in the classroom. Cambridge: Harvard University Press, 1979.

MOITA LOPES, L. P. Oficina de língüística aplicada: a naturesa social e educacional dos processos de ensinolaprendizagem de línguas. Campinas, SP: Mercado de Letras, 1996.

PRETI, D. Problems with the representation of face and its manifestations in the discourse of the 'old-old'. IN: C.M. CaldasCoulthard \& M. Coulthard (eds.). Text and Practices. London: Routledge, 1996.

SHULTZ, J. J., FLORIO, S. E ERICKSON, F. Where's the floor? Aspects of the cultural organization of social relationships in communication at home and in school. In: Gilmore, P. e Glatthorn, A. A. (eds.). Children in and out of school. Washington, D. C.: Center for Applied Linguistics, 1982. 
SHUY, R. Identifying dimensions of classroom language. IN: Judith L. Green e Judith O. Harker (eds.). Multiple perspective analyses of classroom discourse. v. 28, New Jersey: Ablex Publishing Corporation, 1988.

SINCLAIR, J. McH. ; COULTHARD, R. M. Towards an analysis of discourse: the English used by teachers and pupils. Oxford: Oxford University Press, 1975.

TSUI, A. B. M. Introducing classroom interaction. London: Penguin, 1995. 